\title{
Knowledge, Attitudes, and Stigma Related to Dementia Among Illiterate and Literate Older Adults in Shanghai
}

This article was published in the following Dove Press journal: Risk Management and Healthcare Policy

\author{
Tingting Yang $\mathbb{B}^{1, *}$ \\ Yanyan Huang $\mathbb{D}^{2,3, *}$ \\ Xinghui Li \\ Mengying $\mathrm{Li}^{1}$ \\ Suisui $\mathrm{Ma}^{4}$ \\ Guo Xuan ${ }^{5}$ \\ Yihua Jiang $\mathbb{D}^{5}$ \\ Shuangyuan Sun $\mathbb{1 D}^{6}$ \\ Yinghua Yang $\mathbb{D}^{7}$ \\ Zhuochun $\mathrm{Wu}^{\prime}$ \\ Xiangyun Li $\mathbb{D}^{2}$ \\ Ying Wang $\mathbb{B}^{1,8}$
}

'School of Public Health, Fudan University, Shanghai, People's Republic of China; ${ }^{2}$ Department of Geriatrics, Huashan Hospital, Fudan University, Shanghai, People's Republic of China; ${ }^{3}$ Tian Qiao and Chrissy Chen Institute Clinic Translational Research Center, Shanghai, People's Republic of China; ${ }^{4}$ Yuluo Management Consultation Co. Ltd of Shanghai, Shanghai, People's Republic of China; ${ }^{5}$ MedicineMental Health Center of Minhang District/ Minhang Branch, School of Public Health, Fudan University, Shanghai, People's Republic of China; ${ }^{6}$ Shanghai Municipal Center for Disease Control and Prevention, Shanghai, People's Republic of China; ${ }^{7}$ Shanghai Center for Clinical Laboratory, Shanghai, People's Republic of China; ${ }^{8}$ Key Laboratory of Health Technology Assessment, National Health and Family Planning Commission of the People's Republic of China, Fudan University, Shanghai, People's Republic of China

*These authors contributed equally to this work

Correspondence: Ying Wang Email wangying1013@fudan.edu.cn

Xiangyun Li

Email ccwlxy.cool@I63.com
Background: China has the largest population of patients with dementia worldwide, no assessment of illiterate old population's dementia knowledge, attitudes, stigma have been conducted so far in China.

Aim: This study focused on the impact of education on knowledge, attitudes, and stigma related to dementia.

Methods: The community-based sample used in this study was recruited using multi-stage random sampling from residents aged $\geq 60$ years registered in Shanghai. We used the Geriatric Depression Scale (GDS-30) to identify depression, and the Ascertain Dementia 8 questionnaire (AD8) for evaluating participants' cognitive impairment. Knowledge, Attitude, Belief, and Practice scale, Perceptions Regarding Investigational Screening for Memory in Primary Care (PRISM-PC) were used for measuring dementia knowledge, attitudes, stigma. We separated the population into illiterate and literate group, propensity score matching based on age, sex, depression, and cognitive impairment. We calculated the difference of knowledge, attitudes, and stigma related to dementia between illiterate and literate groups.

Results: Two thousand five hundred and eighteen participants completed the survey. After propensity score matching, 186 pairs of matched participants left. The overall correct rate of dementia knowledge was $70.34 \%$. The illiterate group had a lower percentage of correct answers for each knowledge item. The item "Dementia is not a disease, it is forgetfulness due to aging" had the lowest accuracy rate in both groups $(38.71 \%$ vs. $50.54 \%, p=0.022)$. Illiterate older adults were less accepting of dementia than literate older adults. The majority of participants did not agree that: "There is no need to visit a doctor when older people have memory loss, difficulty communicating, or finding words" (56.99\% vs. 68.28\%). Illiterate older adults had higher scores for the items assessing stigma toward dementia than literate older adults.

Conclusion: Dementia-related knowledge and attitudes among community-dwelling older adults in Shanghai may be related to literacy.

Keywords: knowledge, attitudes, stigma, dementia, illiterate elderly

\section{Background}

In different countries around the world, aging demographic shifts are often referred to as "waves"; however, the shift in China can be likened to a "tsunami". 1 The proportion of the Chinese mainland population aged over 60 years increased from $13.26 \%$ to $18.13 \%$ between 2010 and 2019 (177.65-253.88 million people). ${ }^{2,3}$ Over the last two decades, the percentage of the population aged 65 years or older in China increased from $6.96 \%$ to $12.57 \%{ }^{3,4}$ In contrast, a similar increase in the aged 
population (from $7 \%$ to $14 \%$ ) took 115 years in France and 85 years in Sweden. ${ }^{5}$ The 2013 "China Aging Development Report" noted that the severity of the aging problem in China was unprecedented. ${ }^{6}$ Population aging is an important concern because age is a major risk factor for many debilitating and life-threatening conditions, including cancer, cardiovascular disease, and neurodegeneration. ${ }^{7}$ Dementia is a symptom of various neurodegenerative diseases associated with aging. China has the largest population of patients with dementia worldwide, ${ }^{8}$ accounting for approximately $25 \%$ of the entire global population with dementia. ${ }^{9}$

Factors such as tobacco use, harmful use of alcohol, unbalanced diets, hypertension, diabetes, obesity, physical inactivity, social isolation, and cognitive decline are associated with dementia. However, people with more years of formal education may be at a lower risk for dementia than those with fewer years of formal education. ${ }^{10}$ Results from the "Epidemiological Clinicopathological Studies in Europe" collaboration also indicated that longer education duration was associated with decreased dementia risk and greater brain weight, but it had no relationship with neurodegenerative or vascular pathologies. ${ }^{11}$ Several previous studies, including a systematic review and meta-analysis, concluded that lower education was a risk factor for dementia. $^{12-14}$

Despite this evidence, public awareness and knowledge of risk and protective factors for dementia in China remain insufficient. ${ }^{15} \mathrm{~A}$ cross-sectional study using an internet-based questionnaire showed that less than $50 \%$ of participants could accurately identify hypertension and diabetes as risk factors for dementia. ${ }^{15}$ Another study conducted across five representative cities in China indicated general Chinese adults lacked knowledge related to Alzheimer's disease (AD). ${ }^{16}$ Although most participants in that study agreed or strongly agreed that patients with $\mathrm{AD}$ should not be discriminated against, ${ }^{17} 76.6 \%$ had a personal fear of developing $\mathrm{AD} .{ }^{16}$ Previous studies focused on knowledge about and attitudes toward dementia have been conducted among health professionals, ${ }^{18}$ dementia caregivers, ${ }^{19}$ and the general public. However, no such study has involved a large-scale community survey of older adults. ${ }^{15-17}$

Over 47 million people in China over age 50 years are illiterate, ${ }^{20}$ which may mean they are at a higher risk for dementia. However, no study has compared knowledge, attitudes, and stigma relating to dementia between illiterate and literate older adults in China. Since Chinese elderly have lower education than the new generation, Chinese elderly might have more misunderstandings about dementia, these may make a plausible hypothesis for the link between lower education and knowledge, attitudes, and stigma related to dementia. The purpose of the present study was to investigate the impact of education on knowledge, attitudes, and stigma related to dementia.

\section{Methods}

\section{Participants}

The community-based sample used in this study was recruited using multi-stage random sampling from residents aged $\geq 60$ years registered in Xinzhuang town, Shanghai, China. Five of the 55 residential committees in Xinzhuang were randomly selected for participant recruitment in this study. The inclusion criteria were being listed as a registered resident and aged $\geq 60$ years. Potential participants were excluded if they: 1) were deceased or not at home at the time of the survey; 2) showed severe schizophrenia or mental illness; or 3) had severe problems with vision, hearing, or speaking and were unable to actively participate in a face-to-face interview.

\section{Measures}

\section{Definitions of Illiteracy and Literacy}

In this study, illiteracy was defined as older adults that had not attended school or received other instruction in reading. ${ }^{21}$ Literacy was defined as knowledge of both reading and writing at a series of nested levels, ranging from individual words to complete texts. ${ }^{22}$

\section{Mood}

We used the Geriatric Depression Scale (GDS-30) to identify depression in participating older adults. The categories used to classify depression were: 1 ) GDS-30 score of $0-9=$ normal and 2) score of $10-30=$ mild or severe depression. ${ }^{23}$

\section{Cognitive Function}

The Ascertain Dementia 8 questionnaire (AD8) was used to evaluate participants' cognitive impairment. A cut-off score of $\geq 2$ on the informant AD8 was considered to indicate cognitive impairment. ${ }^{24}$

\section{Dementia-Related Knowledge and Attitudes}

Knowledge about and attitudes toward dementia were assessed with the Knowledge, Attitude, Belief, and Practice scale. ${ }^{25}$ This scale comprises six true/false 
questions that assess dementia-related knowledge, and five disagree/neutral/agree questions that assess dementiarelated attitudes.

\section{Stigma Toward Dementia}

Participants' stigma toward dementia was measured with the Perceptions Regarding Investigational Screening for Memory in Primary Care (PRISM-PC), which includes 10 statements related to dementia. These items are scored on a 5-point Likert Scale from $1=$ "strongly disagree" to 5 $=$ "strongly agree". 26

\section{Statistical Analyses}

Age, sex, depression, and cognitive impairment were identified as a priori confounding variables. Propensity score matching with nearest neighbor matching was used to match the two groups of interest (literate and illiterate older adults) using a 1:1 ratio, and adjusted for confounders without replacement using a caliper of 0.02 on the probability scale. ${ }^{27}$ The balance achieved by propensity score matching was assessed using standardized differences, $t$-tests (age), and chi-square tests (sex, depression, and cognitive impairment). An absolute standardized difference between groups $<0.05$ was considered negligible. After the propensity score matching, descriptive statistics were calculated for all variables. Continuous data were presented as mean \pm standard deviation and compared using Student's $t$-tests. Categorical variables were displayed as frequencies and percentages and analyzed using chi-square tests. A two-tailed p-value $<0.05$ was considered statistically significant. All analyses were conducted using Stata 13.0 and SPSS 24.0 software.

\section{Results}

\section{Baseline Characteristics}

In total, 2518 participants completed the survey and were included in the original analyses before propensity score matching. Participants in the illiterate group were older than those in the literate group, and female participants had higher rates of illiteracy. Next, we performed propensity score matching, which included 186 pairs of matched participants (Table 1). After propensity score matching, there were no differences between the groups in age, sex, marital status, smoking, drinking alcohol, depression, and cognitive impairment ( $\mathrm{p}>0.05$, see Table 1). In the illiterate group, the mean age was $77.75 \pm 9.46$ years and $79.57 \%$ were women. Most of these participants did not smoke
(87.63\%) or drink alcohol (88.71\%), and few had depression $(29.57 \%)$ or cognitive impairment $(30.11 \%)$.

\section{Knowledge About Dementia}

The overall correct rate of dementia knowledge was $70.34 \%$. Participants' correct answers to the six dementia items differed between the two groups. Table 2 shows the percentage of correct answers for each item. The illiterate group had a lower percentage of correct answers for each item. The item "Dementia is not a disease, it is forgetfulness due to aging" had the lowest accuracy rate in both groups $(38.71 \%$ vs. $50.54 \%, \mathrm{p}=0.022$ ), followed by "Personality, emotion and behavior can be changed when a person has dementia, such as irritability and lack of sleep" (59.68\% vs. $75.81 \%$, $\mathrm{p}=0.004)$, "Dementia may progress to a more severe form" (65.59\% vs. $80.65 \%, p=0.005)$, "Patients with dementia may suffer from difficulty communicating or finding words" (70.43\% vs. $83.33 \%, p=0.007)$, "Patients with dementia get worse on calculation, understanding, and attention, which may affect daily life" (72.04\% vs. $87.10 \%$, $\mathrm{p}=0.001$ ), and "Senescence forgetfulness progresses with advancing age, even being unable to recognize their families" (76.88\% vs. 83.33\%, p=0.164).

\section{Attitudes Toward Dementia}

Illiterate and literate older adults in Shanghai held different attitudes toward dementia (Figure 1). Illiterate older adults were less accepting of dementia than literate older adults. Overall, the majority of participants did not agree that: "There is no need to visit a doctor when older people have memory loss, difficulty communicating, or finding words" (56.99\% vs. 68.28\%); "There is no need to get medical services when older people get dementia" (61.29\% vs. $73.12 \%)$; "It is shameful to have dementia" (67.20\% vs. $78.49 \%$ ); and "Other people may laugh at me, if my family member gets dementia" (67.74\% vs. $75.81 \%$ ). However, the majority of participants agreed with the statement that "If your friend has dementia, you should treat him/her as usual" (63.98\% vs. $73.12 \%)$.

\section{Stigma Toward Dementia}

In general, illiterate older adults had higher scores for the items assessing stigma toward dementia than literate older adults (Table 3). However, illiterate older adults had lower scores than the literate group on the item "If a person had dementia, they would be considered stupid and unable to do things" ( $2.11 \pm 0.85$ vs. $2.20 \pm 0.99, p=0.338)$. There were significant differences between the two groups for four 
Table I Characteristics of Study Participants Before and After Propensity Score Matching

\begin{tabular}{|c|c|c|c|c|c|c|c|c|}
\hline \multirow[t]{2}{*}{ Characteristics } & \multicolumn{4}{|c|}{ Before Propensity Score Matching } & \multicolumn{4}{|c|}{ After Propensity Score Matching } \\
\hline & $\begin{array}{l}\text { Illiteracy } \\
(n=193)\end{array}$ & $\begin{array}{l}\text { Literacy } \\
(n=2325)\end{array}$ & $\mathbf{t} / \chi^{2}$ & $p$ & $\begin{array}{l}\text { Illiteracy } \\
(n=186)\end{array}$ & $\begin{array}{l}\text { Literacy } \\
(n=186)\end{array}$ & $\mathbf{t} / \chi^{2}$ & $p$ \\
\hline Age, y & $78.19 \pm 9.57$ & $70.11 \pm 7.62$ & -13.835 & $<0.001$ & $77.75 \pm 9.46$ & $78.23 \pm 8.95$ & 0.501 & 0.617 \\
\hline Female & $155(80.3 \mid)$ & $1250(53.76)$ & 50.923 & $<0.001$ & I48 (79.57) & $138(74.19)$ & 1.512 & 0.219 \\
\hline Marital status & & & 74.201 & $<0.001$ & & & 0.047 & 0.828 \\
\hline Married & $119(61.66)$ & $1988(85.5 \mathrm{I})$ & & & $119(63.98)$ & $|2|(65.05)$ & & \\
\hline Single & $74(38.34)$ & $337(14.49)$ & & & $67(36.02)$ & $65(34.95)$ & & \\
\hline Smoke & & & 20.744 & $<0.001$ & & & 3.591 & 0.166 \\
\hline Never & I 70 (88.08) & $1716(73.81)$ & & & $163(87.63)$ & I65 (88.7I) & & \\
\hline Past & $13(6.74)$ & $237(10.19)$ & & & $13(6.99)$ & $6(3.23)$ & & \\
\hline Current & $10(5.18)$ & $372(16.00)$ & & & $10(5.38)$ & I5 (8.06) & & \\
\hline Drink & & & $|8.27|$ & $<0.001$ & & & 4.333 & 0.115 \\
\hline Never & $172(89.12)$ & I $803(77.55)$ & & & I 65 (88.7I) & I59 (85.48) & & \\
\hline Past & II (5.70) & 130 (5.59) & & & II (5.9I) & 7 (3.76) & & \\
\hline Current & $10(5.18)$ & $392(16.86)$ & & & $10(5.38)$ & $20(10.75)$ & & \\
\hline Depression & & & 53.258 & $<0.001$ & & & 0.865 & 0.352 \\
\hline No & $134(69.43)$ & 2047 (88.04) & & & $13 \mid(70.43)$ & I 39 (74.73) & & \\
\hline Yes & $59(30.57)$ & 278 (11.96) & & & 55 (29.57) & $47(25.27)$ & & \\
\hline $\begin{array}{l}\text { Cognitive } \\
\text { impairment }\end{array}$ & & & 79.680 & $<0.001$ & & & 0.013 & 0.910 \\
\hline No & I33 (68.9I) & 2097 (90.19) & & & $130(69.89)$ & $|3|(70.43)$ & & \\
\hline Yes & $60(31.09)$ & $228(9.81)$ & & & $56(30.11)$ & $55(29.57)$ & & \\
\hline
\end{tabular}

items: "If I have dementia, my doctor would not provide best care for my medical problems" $(2.12 \pm 0.72$ vs. 1.91 $\pm 0.77, \mathrm{p}=0.009)$; "If I had dementia, my doctor and other health professionals would not listen to me" $(2.13 \pm 0.74 \mathrm{vs}$. $1.94 \pm 0.75, \mathrm{p}=0.013$ ); "If I had dementia, I would be concerned that my health insurance company would find out" ( $2.26 \pm 0.72$ vs. $1.99 \pm 0.77, \mathrm{p}=0.001$ ); and "If I had dementia, I would be concerned my employer would find out" ( $2.26 \pm 0.72$ vs. $2.04 \pm 0.79, \mathrm{p}=0.005$ ).

\section{Discussion}

In this study, we investigated the knowledge, attitudes, and stigma related to dementia among older adult residents in Shanghai, and assessed the differences between illiterate and literate older adults. To our knowledge, this is the first study on this topic in China. Research suggests that knowledge about dementia among the general public in China remains low. ${ }^{15,17,28}$ In our study, the overall correct percentage of dementia knowledge was $70.34 \%$, which was higher than reported in a previous survey conducted in China $(63.14 \%){ }^{28}$ The knowledge item with the lowest overall score was the general concept of dementia, as more than half of the participants believed that dementia was forgetfulness due to aging rather than a disease. This finding was consistent with previous studies (e.g., 66.4\%, 55\%), ${ }^{17,29}$ suggesting that misconceptions about dementia continue to be common in China. Analysis of the items that investigated knowledge about dementia symptoms and diagnosis showed that many participants were not aware that personality, emotion, and behavior can change when a person has dementia. Participants indicated that they obtained dementia knowledge through: media education (e.g., television, radio, 
Table 2 Percentages of Correct Answers to KOD by Education Level. Statements are Presented from Lowest to Highest Total Accuracy Rates

\begin{tabular}{|c|c|c|c|c|c|c|c|}
\hline \multirow{3}{*}{$\begin{array}{l}\text { Knowledge } \\
\text { Subcategory }\end{array}$} & \multirow[t]{3}{*}{ Statement } & \multirow{3}{*}{$\begin{array}{l}\text { Truel } \\
\text { False }\end{array}$} & \multicolumn{5}{|c|}{ Correct Response (\%) } \\
\hline & & & \multirow{2}{*}{$\begin{array}{c}\text { Total } \\
(\mathbf{N}=372)\end{array}$} & \multicolumn{4}{|c|}{ Education Level } \\
\hline & & & & $\begin{array}{l}\text { Illiteracy } \\
(n=186)\end{array}$ & $\begin{array}{l}\text { Literacy } \\
(n=186)\end{array}$ & $\chi^{2}$ & $\boldsymbol{p}$ \\
\hline General & $\begin{array}{l}\text { Dementia is not a disease, it is forgetfulness due } \\
\text { to aging }\end{array}$ & $\mathrm{F}$ & $44.62 \%$ & $38.71 \%$ & $50.54 \%$ & 5.2652 & 0.022 \\
\hline Symptoms and Diagnosis & $\begin{array}{l}\text { Personality, emotion and behavior can be } \\
\text { changed when a person has dementia, such as } \\
\text { irritability, a lack of sleep }\end{array}$ & $\mathrm{T}$ & $67.74 \%$ & $59.68 \%$ & $75.81 \%$ & 11.0714 & 0.004 \\
\hline Symptoms and Diagnosis & Dementia may progress to a more severe form & $\mathrm{T}$ & $73.12 \%$ & $65.59 \%$ & $80.65 \%$ & 10.7238 & 0.005 \\
\hline Symptoms and Diagnosis & $\begin{array}{l}\text { Dementia patients may suffer from difficulty } \\
\text { communicating or finding words }\end{array}$ & $\mathrm{T}$ & $76.88 \%$ & $70.43 \%$ & $83.33 \%$ & 9.8219 & 0.007 \\
\hline Symptoms and Diagnosis & $\begin{array}{l}\text { Dementia patients get worse on calculation, } \\
\text { understanding and attention, it may affect daily life }\end{array}$ & $\mathrm{T}$ & $79.57 \%$ & $72.04 \%$ & $87.10 \%$ & 13.4686 & 0.001 \\
\hline Symptoms and Diagnosis & $\begin{array}{l}\text { Senescence forgetfulness progresses with } \\
\text { advancing age, even being unable to recognize } \\
\text { their families }\end{array}$ & $\mathrm{T}$ & $80.11 \%$ & $76.88 \%$ & $83.33 \%$ & 3.6137 & 0.164 \\
\hline
\end{tabular}

WeChat); posters around living places; and relatives or acquaintances that suffered from dementia. An international study indicated that specific sociodemographic variables were associated with low knowledge about dementia among the general public, including: young age, low educational attainment, being born in a developing nation, and little prior experience of dementia. ${ }^{30}$ Our results were consistent with the above findings.

Overall, the community-dwelling older adult population in our study held positive attitudes toward people with dementia. In our study, $67.20 \%$ of illiterate older adults disagreed that it is shameful to have dementia. This rate was lower than that reported in another study conducted in Tianjin in which $98.6 \%$ of participants agreed that people with dementia should not be discriminated against. ${ }^{17}$ However, other reports indicated the existence of strongly stigmatizing attitudes toward people with dementia. For example, McParland et al conducted a study in Northern Ireland and found that $37 \%$ of participants believed there was little or no benefit in telling
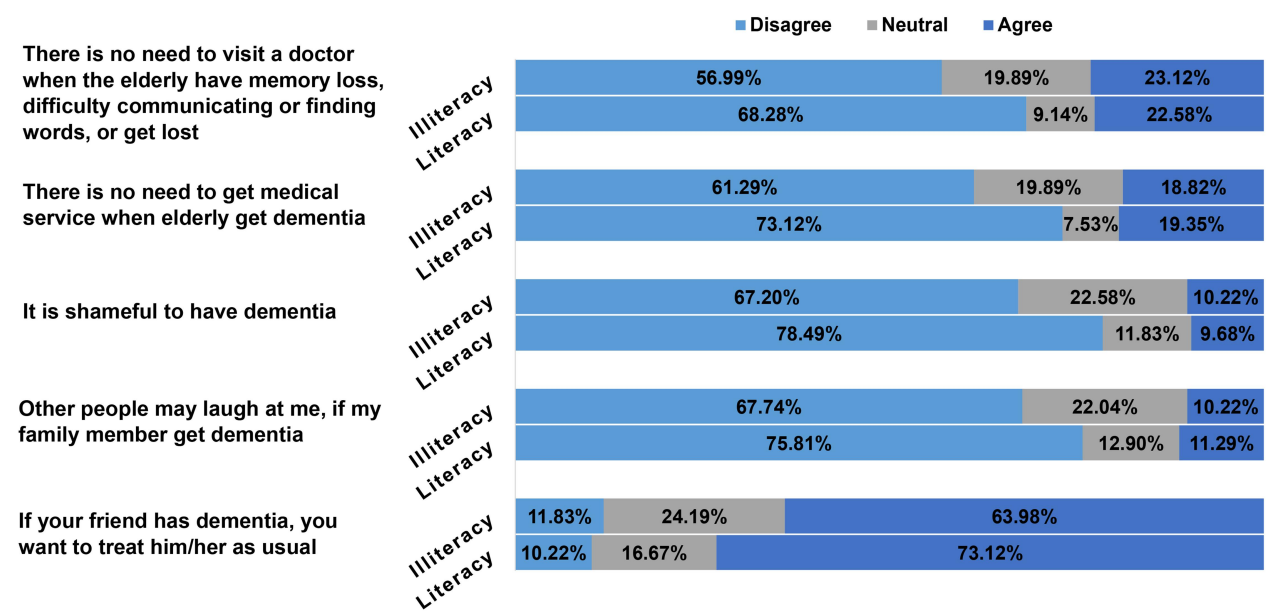

Figure I Attitude distribution according to education level. 
Table 3 Comparison of Stigma Scores Between the Illiteracy and the Literacy Adjusting for Age, Gender, Depression and Cognitive Function

\begin{tabular}{|c|c|c|c|c|c|}
\hline Item & $\begin{array}{l}\text { Total } \\
\text { (Mean士SD) }\end{array}$ & $\begin{array}{l}\text { Illiteracy } \\
\text { (Mean士SD) }\end{array}$ & $\begin{array}{l}\text { Literacy } \\
\text { (Mean士SD) }\end{array}$ & $\mathbf{t}$ & $\mathbf{p}$ \\
\hline If dementia, would not want my family to know & $2.07 \pm 0.90$ & $2.13 \pm 0.90$ & $2.01 \pm 0.89$ & -1.325 & 0.186 \\
\hline If dementia, would feel humiliated by family members, etc. & $2.05 \pm 0.84$ & $2.08 \pm 0.82$ & $2.02 \pm 0.86$ & -0.741 & 0.459 \\
\hline If dementia, no longer taken seriously & $2.07 \pm 0.86$ & $2.08 \pm 0.82$ & $2.06 \pm 0.91$ & -0.180 & 0.857 \\
\hline If dementia, would be considered stupid and unable to do things & $2.16 \pm 0.92$ & $2.11 \pm 0.85$ & $2.20 \pm 0.99$ & 0.959 & 0.338 \\
\hline If knew dementia, would be ashamed or embarrassed & $2.06 \pm 0.84$ & $2.08 \pm 0.77$ & $2.05 \pm 0.90$ & -0.247 & 0.805 \\
\hline If knew dementia, would give up on life & $1.94 \pm 0.73$ & $2.00 \pm 0.72$ & $\mathrm{I} .87 \pm 0.74$ & -1.706 & 0.089 \\
\hline $\begin{array}{l}\text { If dementia, my doctor would not provide best care for my } \\
\text { medical problems }\end{array}$ & $2.01 \pm 0.75$ & $2.12 \pm 0.72$ & $1.91 \pm 0.77$ & -2.640 & 0.009 \\
\hline $\begin{array}{l}\text { If dementia, my doctor and other health professionals would not } \\
\text { listen to me }\end{array}$ & $2.03 \pm 0.75$ & $2.13 \pm 0.74$ & $1.94 \pm 0.75$ & -2.501 & 0.013 \\
\hline $\begin{array}{l}\text { If dementia, concerned that my health insurance company would } \\
\text { find out }\end{array}$ & $2.13 \pm 0.76$ & $2.26 \pm 0.72$ & $1.99 \pm 0.77$ & -3.465 & 0.001 \\
\hline If dementia, concerned my employer would find out & $2.15 \pm 0.76$ & $2.26 \pm 0.72$ & $2.04 \pm 0.79$ & -2.819 & 0.005 \\
\hline
\end{tabular}

someone that they had dementia. ${ }^{31}$ Furthermore, a UK study showed that younger people held more positive attitudes toward dementia than older people. ${ }^{32}$ In our study, literacy proved significant for most (but not all) attitude measures because the illiterate group tended to choose more neutral response options for each item than the literate group.

The general public appears to be fearful of developing dementia and aware of discrimination against people with dementia in some areas. For example, 76.6\% of respondents in a Chinese survey reported a personal fear of developing AD. ${ }^{16}$ Additionally, a survey of the US general public indicated that people with dementia may perceive discrimination by others (e.g., employers) $(55.3 \%)$, being excluded from medical decision-making (55.3\%), and having limited insurance $(44.6 \%){ }^{33}$ Our study suggested that all participants perceived some stigma associated with dementia, although there were few significant differences in perceived stigma between the illiterate and literate groups. In China, commercial health insurance differs from that in Western countries. China's health expenditure mainly comes from the government's general tax revenue, social medical insurance, and residents' outof-pocket spending, and commercial health insurance does not make up the majority of China's health insurance. This means that measuring this variable with one item may not be appropriate for a survey of the general public in China, especially as participants were concerned about their health insurance company finding out if they had dementia. This item could be removed or modified in further studies based on the actual situation in the study setting.

\section{Limitations}

Several potential limitations of this study should be noted. First, our study is not a national survey, Shanghai is city with a better health education knowledge dissemination than most other cities in China, which implies that the percentage of people with low knowledge of dementia in our study might be underestimated. Second, we did not choose the Alzheimer's Disease Knowledge Scale for our study, because the 30item scale is hard to understand for some illiterate elderly, our survey did not cover all aspects of dementia knowledge.

\section{Conclusions}

Our results indicated that dementia-related knowledge and attitudes among community-dwelling older adults in Shanghai may be related to literacy. However, the association between stigma and literacy appears to be relatively weak. 


\section{Data Sharing Statement}

The datasets used and/or analyzed during the current study are available from the corresponding author on reasonable request.

\section{Ethics Approval and Consent to Participate}

Ethical clearance was obtained from Fudan University School of Public Health. The subjects enrolled gave their written informed consent before entering the study, none of patient identifiable features was contained in the study. The written informed consent was read by the reviewer if the participant was illiteracy, then illiterate individual could choose to press his/her fingerprint or give his/her relative the permission to sign. This study complied with the Declaration of Helsinki. Neither the case records nor the data were used for any other purpose. All data accessed complied with relevant data protection and privacy regulations.

\section{Acknowledgments}

We thank Medicine-Mental Health Center of Minhang District and Xinzhuang Community Health Center for supporting the study. We thank Liwen Bianji, Edanz Group China, for editing the English text of a draft of this manuscript.

\section{Author Contributions}

All authors made a significant contribution to the work reported, whether that is in the conception, study design, execution, acquisition of data, analysis and interpretation, or in all these areas; took part in drafting, revising or critically reviewing the article; gave final approval of the version to be published; have agreed on the journal to which the article has been submitted; and agree to be accountable for all aspects of the work.

\section{Funding}

National Key Research and Development Project (2017YFC1310504), the National Natural Science Foundation of China (71673055), Shanghai Leading Academic Discipline Project of Public Health (GWV10.1-XK14), Tianqiao and Chrissy Chen for Translational Research No. 201801, Shanghai Municipal Science and Technology Major Project (No.2018SHZDZX01), and ZJLab. The funder had no role in study design, data collection and analysis, decision to publish or preparation of the manuscript.

\section{Disclosure}

The authors declare that they have no competing interests for this work.

\section{References}

1. Li X, Fan L, Leng SX. The aging tsunami and senior healthcare development in China. J Am Geriatr Soc. 2018;66(8):1462-1468. doi:10.1111/jgs.15424

2. National Bureau of Statistics of China. The sixth nationwide population census. Available from: http://www.stats.gov.cn/tjsj/tjgb/rkpcgb/ qgrkpcgb/201104/t20110428_30327.html. Accessed December 6, 2020.

3. Chinese National Bureau of Statistics of China. Statistical bulletin of the People's Republic of China on the 2019 national economic and social development. Available from: http:/www.stats.gov.cn/tjsj/ zxfb/202002/t20200228_1728913.html. Accessed December 6, 2020.

4. Chinese National Bureau of Statistics of China. Annual data. Available from: https://data.stats.gov.cn/easyquery.htm?cn=C01. Accessed December 6, 2020.

5. World Population Ageing 2013. New York, NY: United Nations Department of Economic and Social Affairs; 2013.

6. He X, Song M, Qu J, et al; Major Program Expert Group. Basic and translational aging research in China: present and future. Protein Cell. 2019;10(7):476-484. doi:10.1007/s13238-019-0617-0

7. Niccoli T, Partridge L. Ageing as a risk factor for disease. Curr Biol. 2012;22(17):R741-R752. doi:10.1016/j.cub.2012.07.024

8. Jia L, Quan M, Fu Y, et al.; Group for the Project of Dementia Situation in China. Dementia in China: epidemiology, clinical management, and research advances. Lancet Neurol. 2020;19(1):81-92. doi:10.1016/S1474-4422(19)30290-X

9. GBD 2016 Dementia Collaborators. Global, regional, and national burden of alzheimer's disease and other dementias, 1990-2016: a systematic analysis for the Global Burden of Disease Study 2016. Lancet Neurol. 2019;18:88-106. doi:10.1016/S1474-4422 (18)30403-4

10. WHO. Dementia toolkit for community workers in low-and middle-income countries: guide for community-based management and care of people with dementia. Available from: https:/iris.wpro. who.int/bitstream/handle/10665.1/14014/9789290618447-eng.pdf. Accessed December 6, 2020.

11. EClipSE Collaborative Members, Brayne C, Ince PG, Keage HA, et al. Education, the brain and dementia: neuroprotection or compensation? Brain. 2010;133(Pt 8):2210-2216. doi:10.1093/ brain/awq185

12. Sharp ES, Gatz M. Relationship between education and dementia: an updated systematic review. Alzheimer Dis Assoc Disord. 2011;25 (4):289-304. doi:10.1097/WAD.0b013e318211c83c

13. Beydoun MA, Beydoun HA, Gamaldo AA, et al. Epidemiologic studies of modifiable factors associated with cognition and dementia: systematic review and meta-analysis. BMC Public Health. 2014;14:643. doi:10.1186/1471-2458-14-643

14. Caamaño-Isorna F, Corral M, Montes-Martínez A, Takkouche B. Education and dementia: a meta-analytic study. Neuroepidemiology. 2006;26(4):226-232. doi:10.1159/000093378

15. Zheng YB, Shi L, Gong YM, et al. Public awareness and knowledge of factors associated with dementia in China. BMC Public Health. 2020;20(1):1567. doi:10.1186/s12889-020-09665-7

16. Zeng F, Xie WT, Wang YJ, et al. General public perceptions and attitudes toward alzheimer's disease from five cities in China. J Alzheimers Dis. 2015;43(2):511-518. doi:10.3233/JAD-141371 
17. Yang HF, Cong JY, Zang XY, et al. A study on knowledge, attitudes and health behaviours regarding alzheimer's disease among community residents in Tianjin, China. J Psychiatr Ment Health Nurs. 2015;22(9):706-714. doi:10.1111/jpm.12259

18. Wang Y, Xiao LD, Luo Y, et al. Community health professionals' dementia knowledge, attitudes and care approach: a cross-sectional survey in Changsha, China. BMC Geriatr. 2018;18(1):122. doi:10. 1186/s12877-018-0821-4

19. Zou Y, Song N, Hu YB, et al. Caregivers' attitude toward disclosure of alzheimer's disease diagnosis in Urban China. Int Psychogeriatr. 2017;29(11):1849-1855. doi:10.1017/S1041610217001132

20. National Bureau of Statistics of China. The sixth nationwide population census. Available from: http://www.stats.gov.cn/tjsj/pcsj/rkpc/ 6rp/indexch.htm. Accessed December 6, 2020.

21. Araújo S, Fernandes T, Huettig F. Learning to read facilitates the retrieval of phonological representations in rapid automatized naming: evidence from unschooled illiterate, ex-illiterate, and schooled literate adults. Dev Sci. 2019;22(4):e12783. doi:10.1111/desc.12783

22. Dehaene S, Cohen L, Morais J, Kolinsky R. Illiterate to literate: behavioural and cerebral changes induced by reading acquisition. Nat Rev Neurosci. 2015;16(4):234-244. doi:10.1038/nrn3924

23. Stanford University. Geriatric depression scale. Available from: https://web.stanford.edu/ yesavage/GDS.english.long.html. Accessed December 6, 2020.

24. Hendry K, Green C, McShane R, et al. AD-8 for detection of dementia across a variety of healthcare settings. Cochrane Database Syst Rev. 2019;3(3):CD011121. doi:10.1002/14651858. CD011121.pub2

25. Dai BZ. Knowledge, Attitude, Belief, and Practice (KABP/KAP) About Alzheimer Disease Among Suspectable Individuals with Mild Cognitive Impairment. Wuhan University; 2012.
26. Boustani M, Perkins AJ, Monahan P, et al. Measuring primary care patients' attitudes about dementia screening. Int J Geriatr Psychiatry. 2008;23(8):812-820. doi:10.1002/gps.1983

27. Cobas Paz R, Raposeiras Roubín S, Abu Assi E, et al. Impact of anticoagulation in patients with dementia and atrial fibrillation. Results of the CardioCHUVI-FA registry. Rev Esp Cardiol (Engl Ed). 2020:S1885-5857(20)30001-3. doi:10.1016/j.rec.2019.10.025

28. Liu D, Cheng G, An L, et al. Public knowledge about dementia in China: a national WeChat-based survey. Int $J$ Environ Res Public Health. 2019;16(21):4231. doi:10.3390/ijerph16214231

29. Li X, Fang W, Su N, et al. Survey in Shanghai communities: the public awareness of and attitude towards dementia. Psychogeriatrics. 2011;11(2):83-89. doi:10.1111/j.1479-8301.2010.00349.x

30. Van Patten R, Tremont G. Public knowledge of late-life cognitive decline and dementia in an international sample. Dementia (London). 2020;19(6):1758-1776. doi:10.1177/1471301218805923

31. McParland P, Devine P, Innes A, Gayle V. Dementia knowledge and attitudes of the general public in Northern Ireland: an analysis of national survey data. Int Psychogeriatr. 2012;24(10):1600-1613. doi:10.1017/S1041610212000658

32. Cheston R, Hancock J, White P. A cross-sectional investigation of public attitudes toward dementia in Bristol and South Gloucestershire using the approaches to dementia questionnaire. Int Psychogeriatr. 2016;28(10):1717-1724. doi:10.1017/S1041610216000843

33. Stites SD, Rubright JD, Karlawish J. What features of stigma do the public most commonly attribute to alzheimer's disease dementia? Results of a survey of the U.S. general public. Alzheimers Dement. 2018;14(7):925-932. doi:10.1016/j.jalz.2018.01.006
Risk Management and Healthcare Policy

\section{Publish your work in this journal}

Risk Management and Healthcare Policy is an international, peerreviewed, open access journal focusing on all aspects of public health, policy, and preventative measures to promote good health and improve morbidity and mortality in the population. The journal welcomes submitted papers covering original research, basic science, clinical \& epidemiological studies, reviews and evaluations, guidelines, expert opinion and commentary, case reports and extended reports. The manuscript management system is completely online and includes a very quick and fair peer-review system, which is all easy to use. Visit http://www.dovepress.com/testimonials.php to read real quotes from published authors. 